\title{
Quantitative analysis of the ternary complex of RNA polymerase, cyclic AMP receptor protein and DNA by fluorescence anisotropy measurements ${ }^{\star}$
}

\author{
Piotr Bonarek ${ }^{\bowtie}$, Sylwia Kędracka-Krok, Barbara Kępys and Zygmunt Wasylewski \\ Department of Physical Biochemistry, Faculty of Biochemistry, Biophysics and Biotechnology, \\ Jagiellonian University, Kraków, Poland
}

Received: 27 April, 2008; revised: 29 August, 2008; accepted: 08 September, 2008

available on-line: 12 September, 2008

\begin{abstract}
The in vitro formation of transcription complexes with Escherichia coli RNA polymerase was monitored using fluorescence anisotropy measurements of labeled fragments of DNA. The multicomponent system consisted of holo or core RNA polymerase (RNAP) and lac or gal promoter fragments of DNA (in different configurations), in the presence or absence of CRP activator protein (wt or mutants) with its ligand, cAMP. Values of the apparent binding constants characterizing the system were obtained, as a result of all processes taking place in the system. The interaction of the promoters with core RNAP in the absence of CRP protein was characterized by apparent binding constants of 0.67 and $1.9 \times 10^{6} \mathrm{M}^{-1}$ for lac166 and gal178, respectively, and could be regarded as nonspecific. The presence of wt CRP enhanced the strength of the interaction of core RNAP with the promoter, and even in the case of gal promoter it made this interaction specific (apparent binding constant $2.93 \times 10^{7} \mathrm{M}^{-1}$ ). Holo RNAP bound the promoters significantly more strongly than core RNAP did (apparent binding constants 1.46 and $40.14 \times 10^{6} \mathrm{M}^{-1}$ for lac166 and gal178, respectively), and the presence of CRP also enhanced the strength of these interactions. The mutation in activator region 1 of CRP did not cause any significant disturbances in the holo RNAP-lac promoter interaction, but mutation in activator region 2 of the activator protein substantially weakened the RNAP-gal promoter interaction.
\end{abstract}

Keywords: RNA polymerase, cAMP receptor protein, fluorescence anisotropy

\section{INTRODUCTION}

Transcription activation by cAMP receptor protein (CRP) from Escherichia coli is a simple example of transcription activation (Busby \& Ebright, 1999). CRP-dependent promoters require only three components: a specific DNA sequence, RNA polymerase enzyme (RNAP), and CRP. RNAP con- sists of five subunits: $\alpha$, which assembles into a dimer, $\beta, \beta^{\prime}, \sigma$ and $\omega$, and it exists in two forms: coreand holo-enzyme. The about $400 \mathrm{kDa}$ core posseses an enzymatic activity necessary for transcription, but it can not recognise specific promoter DNA sequence. The full activity is a result of the interaction of the core with one type of $\sigma$ subunits. The $70-\mathrm{kDa}$ $\sigma^{70}$ subunit is the most abundant one and it is the

\footnotetext{
\Corresponding author: Piotr Bonarek, Department of Physical Biochemistry, Faculty of Biochemistry Biophysics and Biotechnology, Jagiellonian University, Gronostajowa 7, 30-387 Kraków, Poland; tel.: (48 12) 664 6151; fax: (48 12) 664 6902; e-mail: piotr.bonarek@uj.edu.pl

^Presented at the XXXV Winter School "The Structure and Function of Protein and Nucleic Acids" organized by Faculty of Biochemistry, Biophysics and Biotechnology, Jagiellonian University, 23-27 February, 2008, Zakopane, Poland.

Abbreviations: bp, base pair; cAMP, 3',5'-cyclic adenosine monophosphate; CRP, cAMP receptor protein; AR, activating region; $\alpha \mathrm{CTD}$, C-terminal domain of $\alpha$ subunit of RNA polymerase; $\alpha$ NTD, N-terminal domain of $\alpha$ subunit of RNA polymerase; DTT, dithiothreitol; gal178, labeled fragment of promoter gal from Escherichia coli; IPTG, isopropyl $\beta$-D-1-thiogalactopyranoside; lac166, labeled fragment of promoter lac from Escherichia coli; $\mathrm{Ni}^{2+}-\mathrm{NTA}, \mathrm{Ni}^{2+}$-nitrilotriacetate; PAGE, polyacrylamide gel electrophoresis; PMSF, phenylmethanesulfonyl fluoride; RNAP, RNA polymerase; SDS, sodium dodecyl sulfate; wt, wild type.
} 
focus of the present studies. Holo RNAP can bind to specific and nonspecific DNA sequences (deHaseth et al., 1978). The nonspecific interaction allows for a faster search of specific sites by one-dimentional diffusion of RNAP molecule along the DNA template (Kabata et al., 1993; Sakata-Sogawa et al., 2004). Initially, the specific promoter sequence and RNAP form a closed complex which is followed by a series of isomerisation steps. Finally, the RNAP-promoter open complex is created which contains separated strands of double helical DNA and enters the elongation phase (Craig et al., 1998; deHaseth et al., 1998; Saecker et al., 2002; Tsujikawa et al., 2002).

CRP (also called the catabolite gene activator protein - CAP) is a homodimer, and both its subunits consist of two domains (Aiba et al., 1982). The large N-terminal domain binds an allosteric factor: cAMP. The minor C-terminal domain recognises specific DNA sites by a helix-turn-helix motif (McKay \& Steitz, 1981; Weber \& Steitz, 1987; Passner et al., 2000). CRP controls over one hundred promoters (Kolb et al., 1993) that are grouped into three classes: I, II and III (Ushida \& Aiba, 1990; Ebright, 1993; Busby \& Ebright, 1999).

The presence of CRP enhances the promoter-RNAP interaction by creating additional contacts between the activator and other complex components (Malan et al., 1984; Ren et al., 1988; Straney et al., 1989). The number of contacts is different for each promoter class. Only one molecule of CRP is required for initiation of transcription with class I and II CRP-dependent promoters and its DNA site is located upstream of the transcription start point. At class I promoters CRP binds upstream of the site for RNAP and can be centered near positions -93 , -83 or -62 (Zhou et al., 1994; Naryshkin et al., 2000). The CRP site overlaps the site for RNAP on class II promoters. The best-characterized representatives of the class I and II promoters are the lac and the gal ones, for which the CRP sites are centered at positions -61.5 and -41.5 , respectively. Class III CRP-dependent promoters require more than one activator molecule.

Transcription activation at the lac promoter requires formation of a contact between one $\alpha \mathrm{C}$ terminal domain and CRP. The CRP determinant consists of residues 156-164 (AR1). T158 is the most important side-chain for function of AR1 (Niu et al., 1994). Residues $285-289$ and 315-318 form the $\alpha$ subunit "287 determinant". The second "265 determinant" (R265, N268, N294, G296, K298, S299, E302), essential for DNA binding, is responsible for recognition of a specific sequence on the promoter (Gaal et al., 1996; Murakami et al., 1996). The crystallographic structure of the $\alpha$ CTD-CRP-DNA complex confirms the described mechanism (Benoff et al., 2002).
In addition to those mentioned above, transcription activation of the gal promoter requires two additional interactions of CRP with RNAP (Busby \& Ebright, 1999). AR1 of the upstream subunit of CRP interacts with the 287 determinant of $\alpha$ CTD (Bell et al., 1990; Williams et al., 1991; Savery et al., 1998). $\mathrm{AR} 2$, a second CRP determinant consisting of residues H19, H21 and K101 interacts with $\alpha$ NTD determinant, which consists of residues 162-165 (Niu et al., 1996). The active AR2 sequence is located on the distal CRP monomer. It seems that this protein-protein interaction is an electrostatic one between the negative charge on the "165 determinant" and the positive charge on AR2.

AR3, a third CRP determinant consisting of D53, E54, E55 and E58 interacts with residues 593603 of $\sigma^{70}$ subunit. This interaction has also an electrostatic nature, for which the contact between E58 of AR3 and two arginines of $\sigma^{70}$ plays a key role (Rhodius \& Busby, 2000a; 2000b).

As a consequence of the above-mentioned studies and with the use of crystallographic data, molecular models of transcription activation by CRP on lac and gal promoters were generated (Lawson et al., 2004).

However, numerous molecular details concerning these processes are still unknown. Only the knowledge of binding constants enables one to predict the behavior of the molecular system studied at fixed concentrations of reagents. In this report we describe the use of fluorescence anisotropy method to quantitatively analyze the complicated molecular system comprising: RNAP, CRP and DNA. Our research model has three important advantages: i) all measurements are conducted in solution, ii) its sensitivity allows the use of low concentrations of macromolecules, and iii) no protein structure has been modified. Therefore, conditions closely resembling the in vivo state could be simulated. The applied model not only enabled us to confirm earlier results, but also provided new information concerning the role of CRP in regulation of the gene transcription.

\section{MATERIALS AND METHODS}

Buffers. All buffers were prepared from deionized water from a MiliQ system and highest grade chemicals. Buffer A, $50 \mathrm{mM} \mathrm{NaH} \mathrm{PO}_{4^{\prime}} \mathrm{pH}=7.0$, containing $5 \mathrm{mM}$ imidazole and $500 \mathrm{mM} \mathrm{NaCl}$. Buffer B, $40 \mathrm{mM}$ Tris $/ \mathrm{HCl}, \mathrm{pH}=7.9$, containing $300 \mathrm{mM}$ $\mathrm{KCl}$ and $10 \mathrm{mM}$ EDTA. Buffer C, $50 \mathrm{mM}$ Tris/ $\mathrm{HCl}$, $\mathrm{pH}=7.9$, containing $100 \mathrm{mM} \mathrm{KCl}, 1 \mathrm{mM}$ EDTA and $5 \%(\mathrm{v} / \mathrm{v})$ glycerol. Buffer D, same as buffer B, but containing 20\% glycerol. Buffer E, $50 \mathrm{mM}$ Tris/ $\mathrm{HCl}$, $\mathrm{pH}=7.9$, containing $100 \mathrm{mM} \mathrm{KCl}$ and $10 \%(\mathrm{v} / \mathrm{v})$ glyc- 
erol. Buffer F, $10 \mathrm{mM}$ Tris/HCl, $\mathrm{pH}=8.0$, containing $0.1 \mathrm{mM}$ EDTA

\section{Protein expression and purification}

Expression of RNAP subunits. The $\beta, \beta^{\prime}, \sigma^{70}$ and the N-terminal His-tagged $\alpha$ polymerase subunits were purified from E. coli BL21(DE3) carrying plasmids: pHTT7f1-NH $\alpha$ (rpoA) (Tang et al., 1995) for $\alpha$ subunit, pMKSe2 (rpoB) (Severinov et al., 1993) or pET21a+(rpoB) for $\beta$ subunit, pT7 $\beta^{\prime}$ (rpoC) (Zalenskaya et al., 1990) or pET28a+(rpoC) for $\beta^{\prime}$ subunit and pET-21б (rpoD) (Hernandez et al., 1996) for $\sigma^{70}$ subunit. Plasmid pET21a+(rpoB) was constructed by transferring rpoB gene to commercial plasmid pET21a (Novagen) using restriction enzymes: NdeI/HindIII. Plasmid pET28a+ $(r p o C)$ was constructed by transferring rpoC gene to commercial plasmid pET28a (Novagen) using restriction enzymes: $\mathrm{NcoI} / \mathrm{XhoI}$.

Bacterial strains were grown in LB broth with ampicillin at $37^{\circ} \mathrm{C}$ until $\mathrm{OD}_{600}$ reached 0.8 , then protein expression was induced with $1 \mathrm{mM}$ IPTG. The cultures were shaken for additional $3 \mathrm{~h}$ and harvested by centrifugation. The cell pellets were frozen at $-80^{\circ} \mathrm{C}$.

Purification of $\alpha$ subunit. Frozen cell pellet was resuspended in $60 \mathrm{ml}$ of buffer A plus $1 \mathrm{mM}$ PMSF, $1 \mathrm{mM}$ DTT, $0.2 \mathrm{mg} / \mathrm{ml}$ lysozyme, mixed to homogenity and after incubation for $20 \mathrm{~min}$, sonicated eight times with $30 \mathrm{~s}$ pulses at the maximum power setting using the Techpan UD-11 sonicator. The mixture was centrifuged at $30000 \times g, 30 \mathrm{~min}$ at $4^{\circ} \mathrm{C}$, and the supernatant was loaded at $1 \mathrm{ml} / \mathrm{min}$ on a $10-\mathrm{ml} \mathrm{Ni}^{2+}$-NTA agarose column (Novagene) preequilibrated with buffer A. The column was washed with $50 \mathrm{ml}$ of buffer $\mathrm{A}$, the bound proteins were eluted with $20 \mathrm{ml}$ of buffer A plus $300 \mathrm{mM}$ imidazole. Two-milliliter fractions were collected and aliquots of each fraction were analyzed by SDS/12\% PAGE. The fractions containg $\alpha$ subunit (about $90 \%$ purity) were pooled, dialysed overnight against 21 of buffer $\mathrm{D}$ and stored at $-30^{\circ} \mathrm{C}$.

Purification of $\beta, \beta^{\prime}$ and $\sigma^{70}$ subunits. Purification of inclusion bodies formed by all three subunits was conducted according to the method of Tang et al. (1996) with one modification. A $0.2 \%(\mathrm{v} / \mathrm{v})$ Triton X-100 was used in place of n-octyl- $\beta$-D-glucoside. Washed inclusion bodies were resuspended in buffer B plus $10 \%(\mathrm{v} / \mathrm{v})$ glycerol and stored at $-80^{\circ} \mathrm{C}$.

Reconstitution and purification of RNAP. The enzyme was reconstituted from subunits as described previously (Tang et al., 1996). The core or holo RNAP was loaded at $2 \mathrm{ml} / \mathrm{min}$ on a $10-\mathrm{ml} \mathrm{Ni}^{2+}$ NTA column equilibrated with buffer E using a peristaltic pump. The column was then washed with 40 $\mathrm{ml}$ of the same buffer and the bound proteins were eluted with $25 \mathrm{ml}$ of buffer E with $100 \mathrm{mM}$ imidazol.
The fractions containing the required proteins were pooled, diluted four times with buffer $\mathrm{C}$ and loaded at $3 \mathrm{ml} / \mathrm{min}$ on a MonoQ 10/10 HR column preequilibrated with buffer $C$ using Äkta Explorer FPLC system. The column was washed with $50 \mathrm{ml}$ of buffer $\mathrm{C}$ with $0.2 \mathrm{M} \mathrm{KCl}$. The bound proteins were eluted with a gradient of $\mathrm{KCl}$ in buffer $\mathrm{C}(0.2-0.5 \mathrm{M} \mathrm{KCl}$ in $100 \mathrm{ml}$ ). Aliquots of $10 \mu \mathrm{l}$ of the fractions were analysed by $7.5-12 \%$ SDS/PAGE. The fractions containing pure RNAP core $(>98 \%)$ were pooled and dialysed overnight against 0.51 of buffer $\mathrm{C}$ or storage buffer $(50 \mathrm{mM}$ Tris/ $\mathrm{HCl}, \mathrm{pH}=7.9$, containing 100 $\mathrm{mM} \mathrm{KCl}, 1 \mathrm{mM}$ EDTA and 50\% (v/v) glycerol). The fractions in storage buffer were stored at $-80^{\circ} \mathrm{C}$.

Purification of CRP. CRP wt and three point mutants: H19A, H21A, T158A were isolated from E. coli M182 1 crp (Busby et al., 1983) transformed with pHA7 plasmids (Aiba et al., 1982) carrying respective mutant crp genes. The mutations were inserted using the overlap extension method with Pwo polymerase. Cells were grown in LB medium with ampicilin at $37^{\circ} \mathrm{C}$. All proteins were purified as described previously (Malecki et al., 2000). The obtained protein solutions indicated $>97 \%$ purity as judged by SDS/PAGE with Coomassie Brilliant Blue staining.

Amplification and purification of DNA fragments from PCR mixture. A 166-bp DNA fragment of lac promoter (lac166) labeled at 5'-end with fluorescein was synthesized by amplification of a fragment of pUC19 plasmid in a PCR reaction using the following primers:

for -5'-GTA ATC ATG GTC ATA GCT GTT TCC-3', rev -5'-fluorescein-CAG GTT TCC GGA CTG GAA AGC-3',

and a 178-bp DNA fragment labeled at 5'-end with fluorescein containing gal promoters $\mathrm{P}_{1}$ and $\mathrm{P}_{2}$ (gal178) was synthesized by amplification of a fragment of pSA509 plasmid (Choy \& Adhya, 1992) in a PCR reaction using the following primers:

for -5'-fluorescein-CGG CTA AAT TCT TGT GTA AAC-3', rev -5'-ATT TGC TGC AGT AAT TGC ACA-3'.

Thus, the fluorescent dye was placed about 60 nucleotides upstream of the CRP-binding site.

The PCR mixture was 4-fold diluted with buffer F and loaded on a MonoQ 10/10 HR column pre-equilibrated with the same buffer F. After loading it was washed with $20 \mathrm{ml}$ of buffer $\mathrm{F}$ and a gradient of $\mathrm{NaCl}$ (in buffer F) from 0 to $1.0 \mathrm{M}$ was used to elute the DNA fragment. Separation of the obtained fractions was monitored by absorbance measurement at $260 \mathrm{~nm}$ and ethidium bromide-stained agarose gel electrophoresis of DNA samples.

Fluorescence anisotropy measurements. The experiments were performed with a Fluorolog-3 spectrofluorometer (JY Horiba) using photon counting technique and an L-format setup. The configura- 
tion of monochromators was 1:2 (i.e., single-grating at excitation, double-grating at emission position). Samples containing fluorescein-labeled oligodeoxyribonucleotides were excited at $490 \mathrm{~nm}$. The intensity of fluorescence emission at $520 \mathrm{~nm}$ at vertical-vertical $\left(\mathrm{I}_{\mathrm{VV}}\right)$ and vertical-horizontal $\left(\mathrm{I}_{\mathrm{VH}}\right)$ directions was determined. The fluorescence anisotropy $(\mathrm{r})$ was calculated according to equation:

$r=\frac{I_{V V}-G I_{V H}}{I_{V V}+2 G I_{V H}}$

The G-factor (defined as the ratio of fluorescence intensity measured in horizontal-vertical $\left(\mathrm{I}_{\mathrm{HV}}\right)$ to horizontal-horizontal $\left(\mathrm{I}_{\mathrm{HH}}\right)$ polarizator positions) was determined in preliminary measurements and remained fixed as a constant value during proper experiments. The chosen excitation and emission bandpasses depended on sample concentration and gave the intensity of fluorescence in all polarizator positions within the range $0.5-1.5 \times 10^{6} \mathrm{cps}$. Temperature of $25.0 \pm 0.1^{\circ} \mathrm{C}$ was maintained by a Julabo F25 water-circulated thermostat chamber. Samples were incubated at $25^{\circ} \mathrm{C}$ for $30 \mathrm{~min}$ before conducting experiments. All measurements were carried out in a $10 \mathrm{~mm}$-pathlength quartz cuvette in titration buffer C. Before measurements all components were simultaneously dialysed against the same portion of titration buffer. Afterwards, the samples were centrifuged $\left(25000 \times g, 10 \mathrm{~min}, 20^{\circ} \mathrm{C}\right)$ and the concentrations were determined using Bradford reagent for RNAP and extinction coefficients of $\varepsilon_{278}=40800 \mathrm{M}^{-1} \mathrm{~cm}^{-1}$ and $\varepsilon_{259}=14650 \mathrm{M}^{-1} \mathrm{~cm}^{-1}$ for CRP and cAMP, respectively. The DNA concentration was calculated assuming $\mathrm{A}_{260}=1.0$ corresponds to dsDNA concentration of $50 \mu \mathrm{g} / \mathrm{ml}$; the molecular mass of the examined promoter fragments was 650 $\mathrm{Da} / \mathrm{bp}$ on average. The titrations were performed by adding to lac166 or gal178 solution $(1800 \mu \mathrm{l}$ of $20-40 \mathrm{nM})$ small aliquots $(2-20 \mu \mathrm{l})$ of the stock solution of holo or core RNA polymerase $(5-10 \mu \mathrm{M})$ containing DNA in appropriate concentration (the same as in the solution being titrated). All measurements were carried out in the presence of $200 \mu \mathrm{M}$ cAMP which is more than sufficient to saturate the available anti-periplanar binding sites of CRP. When the experiment was carried out with CRP protein, the initial sample and titrating solution also included it. After each addition the solution was stirred and equilibrated to reach the desired temperature. Measured anisotropy represented the mean value of at least two repetitions, which in turn involved 3-5 accumulation points. A single experiment included about 30 additions which corresponded to about 20-fold molar excess of RNAP over DNA.

Calculations. Two binding models of the studied interactions were used. The first model, named $\mathrm{B}$, described the mechanism of the reaction according to equation:

$\mathrm{A}+\mathrm{B} \Leftrightarrow \mathrm{AB}$, with one binding constant $K_{\mathrm{b}}$.

The second one, named $\mathrm{BB}$, described the mechanism of the reaction according to equations:

$\mathrm{A}+\mathrm{B} \Leftrightarrow \mathrm{AB}$ and

$\mathrm{AB}+\mathrm{B} \Leftrightarrow \mathrm{AB}_{2}$, with two binding constants: $K_{\mathrm{b} 1}$ and $K_{\mathrm{b} 2}$.

More sophisticated models did not give a better fit, but generated large discrepancies and errors of the fitted parameters. Besides, the sequence model of binding was more preferable. Estimation of the parameters for systems of equations was performed with the program DynaFit (Kuzmic, 1996) using data obtained experimentally.

\section{RESULTS}

\section{DNA-holo RNAP interaction and CRP influence on transcription complex formation}

We observed an increase of fluorescence anisotropy of labeled DNA with increasing RNAP concentration, in the absence or presence of CRP. Additionally, the increase of the anisotropy was sensitive to the composition and concentration of the reagents.

During titration experiments up to 5-fold increase of fluorescence anisotropy was observed. The influence of protein binding on the fluorescence emission spectrum of DNA was also checked. The addition of CRP (or its mutants) did not change the fluorescence intensity, while the presence of RNAP holoenzyme caused a $20 \%$ and $25 \%$ decrease in fluorescence intensity for lac166 and gal178, respectively (not shown). The analysis of total fluorescence changes (according to the sum: $\mathrm{I}_{\mathrm{VV}}+2 \mathrm{GI}_{\mathrm{VH}}$ ) also confirmed this result.

Table 1. Binding parameters obtained for lac166-holo RNAP interaction according to model $B$ at various concentrations of CRP variants

\begin{tabular}{lllll}
\hline Protein & $\begin{array}{l}\text { [CRP] } \\
(\mathrm{nM})\end{array}$ & $\begin{array}{l}K_{\mathrm{app}} \\
\left(10^{6} \mathrm{M}^{-1}\right)\end{array}$ & $\mathrm{r}_{\text {lac166 }}$ & $\mathrm{r}_{\text {lac166holo }}$ \\
\hline \multirow{4}{*}{ CRPwt } & 0 & $1.46 \pm 0.15$ & $0.051 \pm 0.001$ & $0.286 \pm 0.013$ \\
& 400 & $3.69 \pm 0.32$ & $0.051 \pm 0.002$ & $0.225 \pm 0.005$ \\
& 860 & $4.78 \pm 0.36$ & $0.054 \pm 0.002$ & $0.216 \pm 0.003$ \\
& 2000 & $3.86 \pm 0.30$ & $0.060 \pm 0.002$ & $0.225 \pm 0.004$ \\
& 0 & $3.40 \pm 0.42$ & $0.041 \pm 0.003$ & $0.181 \pm 0.005$ \\
\hline CRPT158A & 400 & $2.74 \pm 0.30$ & $0.044 \pm 0.002$ & $0.187 \pm 0.005$ \\
& 800 & $4.77 \pm 0.49$ & $0.042 \pm 0.002$ & $0.171 \pm 0.003$ \\
& 2000 & $6.22 \pm 0.50$ & $0.052 \pm 0.002$ & $0.166 \pm 0.002$ \\
\hline
\end{tabular}




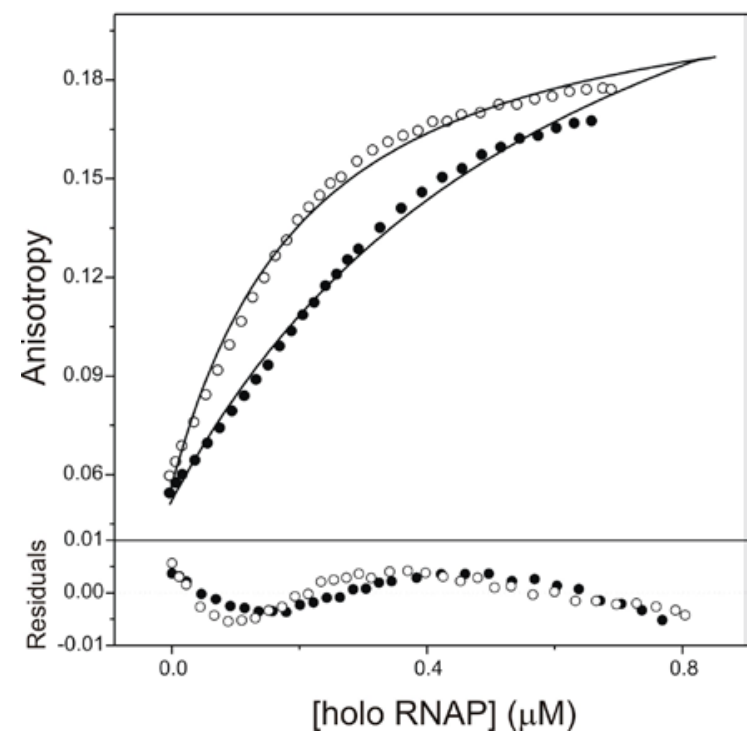

Figure 1. Fluorescence anisotropy analysis of holo RNAP-lac166 interactions in the absence of CRP $(\bullet)$ and at $860 \mathrm{nM}$ CRP wt (O).

Solid lines are representative fitting curves according to model B. The goodness of fit is shown by distribution of residuals (lower panel).

The study of transcription complex formation between holo RNAP and lac166 was performed in the absence of activator protein or at increasing concentrations of CRP wt or mutant T158A (400 nM, $800 \mathrm{nM}$ and $2000 \mathrm{nM}$ ). In all cases an increase of fluorescence anisotropy during titration was observed, ranging from $0.04-0.06$ to $0.14-0.18$ (Fig. 1). The fluorescence anisotropy increased more rapidly in the presence of CRP than in its absence.

The measured changes for lac166 in all cases could be satisfactorily fitted by the model B:

lac166 + RNAPholo $\Leftrightarrow$ lac166-RNAPholo.

The solid line in Fig. 1 is an example of the fitting procedure according to model $\mathrm{B}$. The obtained values of the binding constant $K_{\mathrm{app}}$ and the calculated theoretical anisotropy for free lac166 $\left(\mathrm{r}_{\text {lac166 }}\right)$ and lac166 bound to one molecule of holoenzyme $\left(\mathrm{r}_{\text {lac166holo }}\right)$ are depicted in Table 1.

A series of titration experiments were also performed for gal178 fragment without CRP or with one of the following: CRPwt, H19A or H21A. The observed anisotropy values strongly depended on the concentration of holo RNAP and also on of CRP. The range of anisotropy changes at a given CRP concentration reached a few hundred percent (see Fig. 2). The initial value of fluorescence anisotropy for gal178 was of 0.05 , similar to the value obtained for lac166. However, the final anisotropy was highly variable. The biggest changes were observed in the absence of CRP. Even a small amount of CRP significantly decreased the amplitude of the change. A correlation between the initially observed anisotropy value and CRP concentration was also observed. It was probably a result of nonspecific protein-DNA interactions. This could also explain the smallest changes of anisotropy at the highest CRP concentration $(2 \mu \mathrm{M})$, about $180 \%$ for CRPwt and $220 \%$ for the mutants. Increasing concentration of CRP changed the shape of the titration curves especially at low RNAP concentrations. The bending effect was significant in the case of mutants and was smaller for CRPwt at a 5-fold molar RNAP excess over DNA. More plain anisotropy changes of the shape were observed at higher, over $1 \mu \mathrm{M}$, CRP concentration.

The titration curves described above were analyzed with the DynaFit program according to model $\mathrm{BB}$, which corresponded to the following reactions:

gal178 + RNAPholo $\Leftrightarrow \quad$ [gal178-RNAPholo]

[gal178-RNAPholo] + RNAPholo $\Leftrightarrow$ [gal178-RNAPholo ${ }_{2}$ ]

The averaged values of association constants of $4.014 \pm 0.935 \times 10^{7} \mathrm{M}^{-1}$ and $7.7 \pm 2.3 \times 10^{5} \mathrm{M}^{-1}$ obtained for experiments without CRP and with CRP could be related to specific and nonspecific holoenzyme-gal178 interaction, respectively. The presence of CRP made the analysis much more difficult. However, the values of $K_{1 \text { ass }}$ and $K_{\text {2ass }}$ increased with increasing CRP concentration, calculated values of anisotropy parameters: $r_{g a l 178}$, $\mathrm{r}_{\text {gal178holo' }} \mathrm{r}_{\text {gal178holo2 }}$ were often unlikely or incorrect (close to zero or $>0.4$ ). Also the binding constants reached very high values under the same conditions. The distribution of the residuals in the range of low RNAP concentrations indicated the existence of an interaction characterized by a high association constant, which could not be determined correctly by the BB model. We decided to modify the $\mathrm{BB}$ model by introduction of a fixed (equal to $10^{9} \mathrm{M}^{-1}$ ) first binding constant in order to limit the number of fitted parameters and to simplify the calculations. This value of the constant was the lowest one, which made it possible to obtain coherent results. Specified in this way, the BB model better described the titration curves obtained for the interaction of holo RNAP with gal178 in the presence of CRP (Fig. 2 and Table 2).

\section{DNA-core RNAP interaction in the presence or ab- sence of CRP}

Similar titration experiments were performed for the interaction of core RNAP with DNA. These measurements were done only for CRPwt. The 


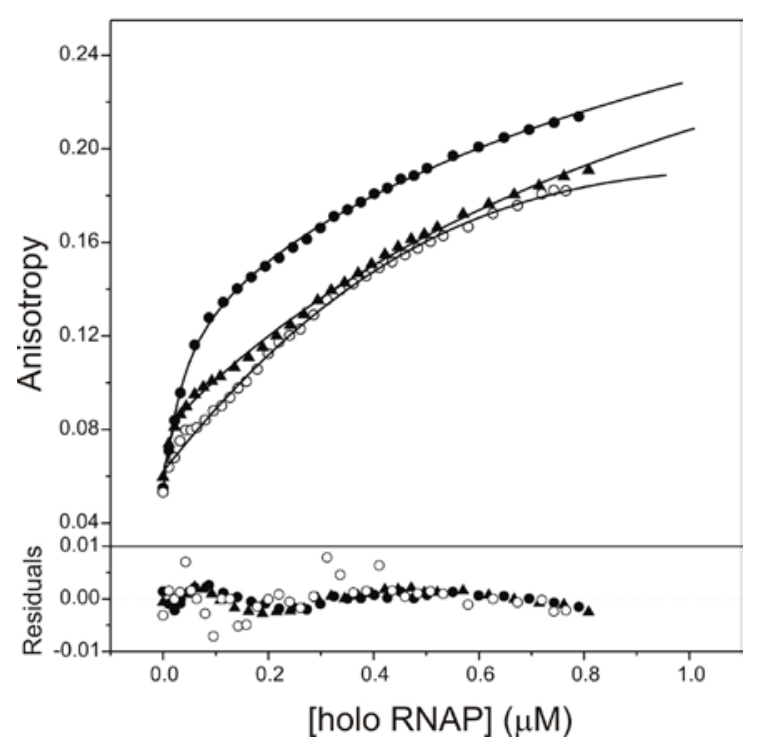

Figure 2. Isotherms of holo RNAP-gal178 interactions in the absence of CRP $(\bullet)$, at $100 \mathrm{nM}(O)$ and $800 \mathrm{nM}(\Delta)$ CRP wt.

Solid lines are representative fitting curves according to model BB. The goodness of fit is shown by the distribution of residuals (lower panel).

quantum yield of fluorescence changed during titration in the range of $20 \%$.
The interaction of core RNAP with lac166 was accompanied by anisotropy changes smaller (about $300 \%$ ) than those caused by the holoenzyme. The presence of CRP caused an increase of fluorescence anisotropy changes at each point of the titration curve as well as an increase of the final anisotropy (compare in Fig. 3). The simplest model B described the experimental data very well regardless of the presence of CRP.

lac166 + RNAPcore $\Leftrightarrow$ lac166-RNAPcore.

The obtained parameters are shown in Table 3 . The average value of the association constant in the presence of CRP was $1.4 \times 10^{7} \mathrm{M}^{-1}$, about twice higher than without the activator protein, however, the calculated anisotropy values of studied system did not change.

The experimental data obtained for the interaction of core RNA with gal178 in the absence of CRP could also be adequately fitted by model B (see black points on Fig. 4):

gal178 + RNAPcore $\Leftrightarrow$ gal178-RNAPcore.

The calculated binding parameters are presented in Table 4. However, the addition of the ac-

Table 2. The binding parameters obtained for gal178-holo-RNAP interaction according to BB model at various concentrations of CRP variants ${ }^{\dagger}$

\begin{tabular}{|c|c|c|c|c|c|c|}
\hline Protein & $\begin{array}{l}{[\mathrm{CRP}]} \\
(\mathrm{nM})\end{array}$ & $\begin{array}{l}K_{1 \mathrm{app}} \\
\left(10^{6} \mathrm{M}^{-1}\right)\end{array}$ & $\begin{array}{l}K_{2 \mathrm{app}} \\
\left(10^{6} \mathrm{M}^{-1}\right)\end{array}$ & $\mathrm{r}_{\text {gal178 }}$ & $\mathrm{r}_{\text {gal178holo }}$ & $\mathrm{r}_{\text {gal178holo2 }}$ \\
\hline & 0 & $40.14 \pm 9.35$ & $0.77 \pm 0.23$ & $0.052 \pm 0.002$ & $0.126 \pm 0.008$ & $0.348 \pm 0.033$ \\
\hline \multirow{8}{*}{ CRPwt } & 10 & 1000 & $1.29 \pm 0.08$ & $0.053 \pm 0.001$ & $0.075 \pm 0.001$ & $0.301 \pm 0.008$ \\
\hline & 30 & 1000 & $1.05 \pm 0.09$ & $0.052 \pm 0.002$ & $0.067 \pm 0.001$ & $0.315 \pm 0.012$ \\
\hline & 100 & 1000 & $1.26 \pm 0.11$ & $0.055 \pm 0.002$ & $0.069 \pm 0.001$ & $0.309 \pm 0.011$ \\
\hline & 400 & 1000 & $1.88 \pm 0.13$ & $0.057 \pm 0.002$ & $0.077 \pm 0.001$ & $0.293 \pm 0.007$ \\
\hline & 800 & 1000 & $1.40 \pm 0.12$ & $0.059 \pm 0.002$ & $0.074 \pm 0.001$ & $0.305 \pm 0.011$ \\
\hline & 1200 & 1000 & $0.83 \pm 0.08$ & $0.060 \pm 0.001$ & $0.085 \pm 0.001$ & $0.361 \pm 0.016$ \\
\hline & 1600 & 1000 & $1.64 \pm 0.10$ & $0.062 \pm 0.001$ & $0.082 \pm 0.001$ & $0.281 \pm 0.006$ \\
\hline & 2000 & 1000 & $1.99 \pm 0.09$ & $0.101 \pm 0.001$ & $0.121 \pm 0.001$ & $0.272 \pm 0.003$ \\
\hline \multirow{7}{*}{ CRPH19A } & 10 & $60 \pm 12$ & $0.42 \pm 0.17$ & $0.048 \pm 0.001$ & $0.119 \pm 0.004$ & $0.406 \pm 0.083$ \\
\hline & 30 & $122 \pm 41$ & $0.35 \pm 0.17$ & $0.052 \pm 0.002$ & $0.105 \pm 0.003$ & $0.489 \pm 0.140$ \\
\hline & 100 & $166 \pm 77$ & $0.19 \pm 0.23$ & $0.051 \pm 0.002$ & $0.103 \pm 0.004$ & $0.714 \pm 0.643$ \\
\hline & 800 & $151 \pm 37$ & $0.80 \pm 0.13$ & $0.059 \pm 0.001$ & $0.110 \pm 0.002$ & $0.337 \pm 0.021$ \\
\hline & 1200 & $598 \pm 156$ & $1.44 \pm 0.09$ & $0.075 \pm 0.001$ & $0.120 \pm 0.001$ & $0.287 \pm 0.005$ \\
\hline & 1600 & $242 \pm 68$ & $1.16 \pm 0.13$ & $0.067 \pm 0.001$ & $0.115 \pm 0.002$ & $0.314 \pm 0.011$ \\
\hline & 2000 & 1000 & $1.75 \pm 0.10$ & $0.088 \pm 0.001$ & $0.114 \pm 0.001$ & $0.263 \pm 0.004$ \\
\hline \multirow{7}{*}{ CRPH21A } & 10 & $41 \pm 17$ & $0.76 \pm 0.30$ & $0.052 \pm 0.002$ & $0.107 \pm 0.008$ & $0.300 \pm 0.041$ \\
\hline & 100 & 1000 & $0.53 \pm 0.08$ & $0.053 \pm 0.002$ & $0.081 \pm 0.001$ & $0.402 \pm 0.036$ \\
\hline & 400 & $697 \pm 745$ & $0.46 \pm 0.11$ & $0.057 \pm 0.002$ & $0.083 \pm 0.002$ & $0.467 \pm 0.070$ \\
\hline & 800 & $116 \pm 60$ & $0.16 \pm 0.13$ & $0.059 \pm 0.002$ & $0.093 \pm 0.003$ & $0.932 \pm 0.586$ \\
\hline & 1200 & $437 \pm 381$ & $0.58 \pm 0.16$ & $0.060 \pm 0.002$ & $0.092 \pm 0.003$ & $0.384 \pm 0.055$ \\
\hline & 1600 & 1000 & $1.17 \pm 0.12$ & $0.062 \pm 0.002$ & $0.092 \pm 0.001$ & $0.314 \pm 0.013$ \\
\hline & 2000 & 1000 & $1.42 \pm 0.14$ & $0.078 \pm 0.002$ & $0.104 \pm 0.001$ & $0.267 \pm 0.008$ \\
\hline
\end{tabular}

${ }^{\dagger}$ Fixed value of $K_{\mathrm{app} 1}$ equal to $1 \times 10^{9} \mathrm{M}^{-1}$ was used in some analyses (for explanation, see Results). 
Table 3. Binding parameters obtained for lac166-core RNAP interaction according to model B

\begin{tabular}{llll}
\hline $\begin{array}{l}\text { [CRPwt] } \\
(\mathrm{nM})\end{array}$ & $\begin{array}{l}K_{\text {app }} \\
\left(10^{6} \mathrm{M}^{-1}\right)\end{array}$ & $\mathrm{r}_{\text {lac166 }}$ & $\mathrm{r}_{\text {lac166core }}$ \\
\hline & $0.75 \pm 0.03$ & $0.048 \pm 0.000$ & $0.274 \pm 0.005$ \\
0 & $0.82 \pm 0.01$ & $0.049 \pm 0.000$ & $0.257 \pm 0.002$ \\
& $0.44 \pm 0.06$ & $0.047 \pm 0.000$ & $0.145 \pm 0.009$ \\
\hline \multirow{2}{*}{100} & $1.56 \pm 0.06$ & $0.047 \pm 0.001$ & $0.222 \pm 0.003$ \\
& $1.25 \pm 0.04$ & $0.049 \pm 0.001$ & $0.223 \pm 0.003$ \\
\hline
\end{tabular}

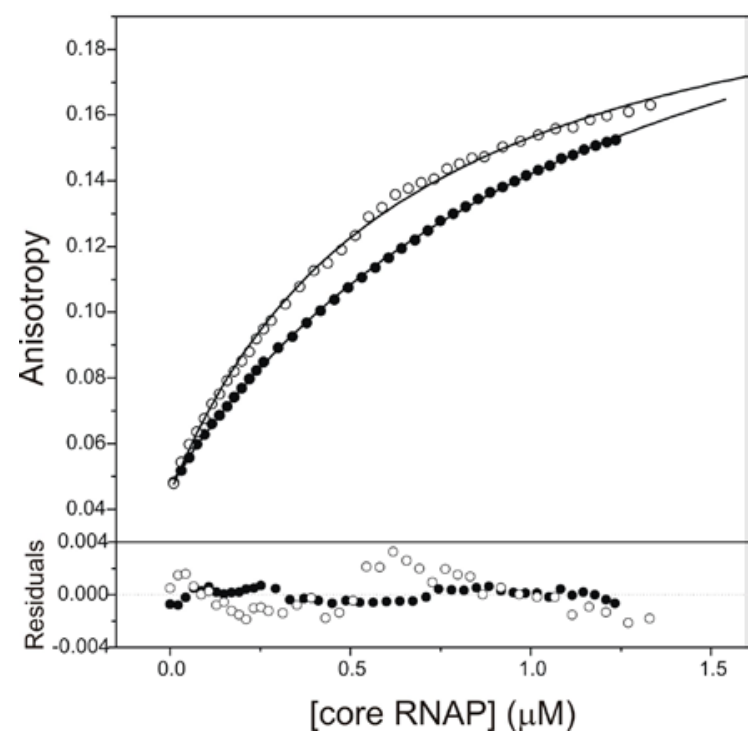

Figure 3. Isotherms of core RNAP-lac166 interactions in the absence of CRP (๑) and at $100 \mathrm{nM}(O)$ CRP wt.

Solid lines are representative fitting curves according to model B. The goodness of fit is shown by the distribution of residuals (lower panel).

tivator protein changed the course of the titration curves and made model B improper. The BB model turned out good enough to describe the obtained data (see open points on Fig. 4).

The avarage value of the association constant for the core RNAP-gal178 interaction measured without CRP was two times higher than for lac166. In the presence of $100 \mathrm{nM}$ CRPwt the first binding constant for the core RNAP-gal178 interaction was equal to $2.93 \times 10^{7} \mathrm{M}^{-1}$ and was 100 fold higher than the second one (Table 4 ).

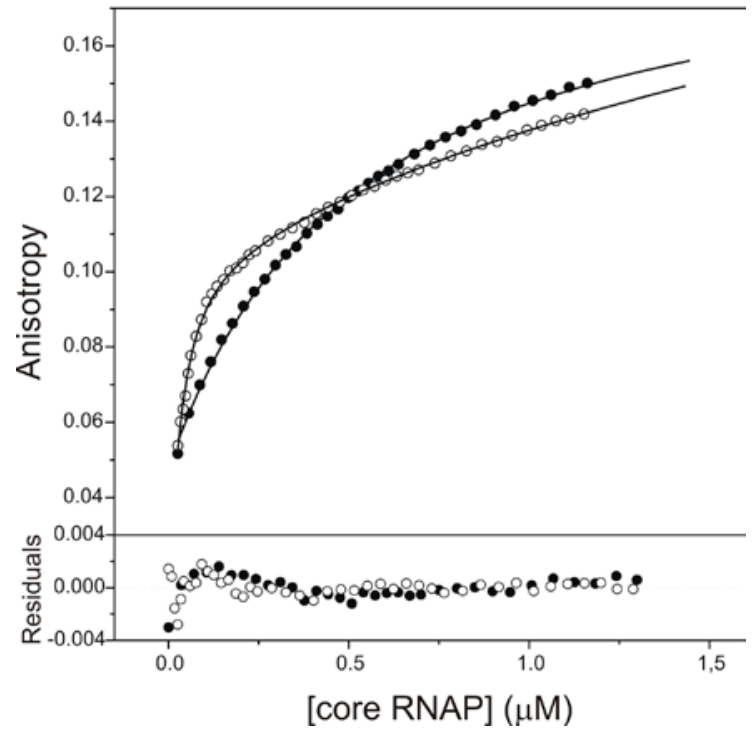

Figure 4. Isotherms of core RNAP-gal178 interactions in the absence of CRP (๑) and at $100 \mathrm{nM}(O)$ CRP wt.

The solid line corresponds to the best fit according model $B$ in the absence of CRP, and according to model BB in the presence of CRP. The goodness of fit is shown by distribution of residuals (lower panel).

\section{DISCUSSION}

The initial value of the fluorescence anisotropy was in the range from 0.04 to 0.06 , and increased in the presence of CRP. The specific interaction between CRP and DNA is quite strong, the association constants have been reported in the range from $10^{7}$ to $10^{10} \mathrm{M}^{-1}$ (Ebright et al., 1989; Takahashi et al., 1989; Heyduk \& Lee, 1990; Pyles \& Lee, 1998; Leu et al., 1999), which indicates that even a low CRP concentration causes saturation of the specific sequence. On the other hand, the association constant of a nonspecific interaction was reported at about $10^{4}$ $\mathrm{M}^{-1}$ (Giraud-Panis et al., 1994). Hence, the increase of anisotropy in the presence of high, micromolar CRP concentration was a result of nonspecific interactions.

The final values of the observed anisotropy were in the range from 0.14 to 0.18 . These values result from an immobilization of DNA ends, an effect

Table 4. The binding parameters obtained for gal178-core RNAP interaction in the absence of CRPwt according to model $B$ and in the presence of CRP wt according to model $\mathrm{BB}^{+}$

\begin{tabular}{llllll}
\hline [CRPwt] $(\mathrm{nM})$ & $\begin{array}{l}K_{1 \text { app }} \\
\left(10^{6} \mathrm{M}^{-1}\right)\end{array}$ & $\begin{array}{l}K_{2 a \mathrm{p} p} \\
\left(10^{6} \mathrm{M}^{-1}\right)\end{array}$ & $\mathrm{r}_{\text {gal178 }}$ & $\mathrm{r}_{\text {gal178core }}$ & $\mathrm{r}_{\text {gal178core2 }}$ \\
\hline \multirow{2}{*}{0} & $1.66 \pm 0.05$ & - & $0.055 \pm 0.001$ & $0.194 \pm 0.002$ & - \\
& $2.13 \pm 0.08$ & - & $0.056 \pm 0.001$ & $0.188 \pm 0.002$ & - \\
\hline \multirow{3}{*}{100} & $39.17 \pm 5.13$ & $0.40 \pm 0.08$ & $0.050 \pm 0.001$ & $0.100 \pm 0.002$ & $0.256 \pm 0.019$ \\
& $24.52 \pm 2.65$ & $0.24 \pm 0.10$ & $0.052 \pm 0.001$ & $0.106 \pm 0.002$ & $0.267 \pm 0.045$ \\
& $24.35 \pm 3.42$ & $0.24 \pm 0.10$ & $0.053 \pm 0.001$ & $0.100 \pm 0.002$ & $0.278 \pm 0.051$ \\
\hline
\end{tabular}


of protein-DNA interactions in the process of complex formation. In studies conducted under similar conditions anisotropy equal to 0.26 was reported (Vogel et al., 2002). This value is similar to the fitted final anisotropy in the majority of our experiments.

There are two sites on both promoters, P1 and P2, for specific association with RNAP. They are much closed to each other; a shift is equal to $5 \mathrm{bp}$ and $22 \mathrm{bp}$ for lac166 and gal178, respectively. A simultaneous binding of two RNAP molecules to both sites is impossible (Nisseley et al., 1971; Yu \& Reznikoff, 1985; Choy \& Adhya, 1993). On the other hand, RNAP can bind to DNA nonspecifically. Hence, two molecules of the enzyme can bind to DNA, but the association constant for one of them should be lower than the other one which describes the specific binding. Indeed, we have observed this discrepancy in the obtained parameters for gal178 complexes, but not in the case of lac166, probably because a free fragment of DNA sufficiently long (70 bp) to bind RNAP nonspecifically is present only in the specific gal178-RNAP complex. This confirms the footprinting data which indicate that an 80$90 \mathrm{bp}$ long promoter sequence is protected during DNA-RNAP complex formation (Taniguchi et al., 1979; Taniguchi \& de Crombrugghe, 1983; Ozoline \& Tsyganov, 1995).

The results obtained in the studies of the interactions of both promoter fragments with core RNAP without CRP, were analysed according to model B. Two binding constants equal to 0.67 and $1.9 \times 10^{6} \mathrm{M}^{-1}$ (average values from Tables 3 and 4) were observed for lac166 and gal178, respectively. These low values are typical for nonspecific of enzyme-DNA association, and they are close to the binding constant of the nonspecific interactions equal to $2 \times 10^{6} \mathrm{M}^{-1}$ determined earlier, although that experiment was conducted at a higher ionic strength (deHaseth et al., 1978). The nonspecific association explains well the one-molecule mechanism in case of the gal178-core RNAP interaction. As a consequence of this type of interaction, the symmetrical binding of the first molecule to the promoter excluded the binding of the second one.

The specific binding constants in the case of holo RNAP are in the range from $10^{6} \mathrm{M}^{-1}$ for weak to $10^{14} \mathrm{M}^{-1}$ for strong promoters. The binding constants measured using kinetic experiments are 1.78 $\times 10^{6} \mathrm{M}^{-1}$ for lac promoter at $25^{\circ} \mathrm{C}$ (Liu et al., 2003) and for a stronger promoter, laclUV5, $4.4 \times 10^{6} \mathrm{M}^{-1}$ at $30^{\circ} \mathrm{C}$ (Ross \& Gourse, 2005). The binding constant for lac and holo RNAP is $10^{9} \mathrm{M}^{-1}$ at $4^{\circ} \mathrm{C}$ (Roy et al., 2004) and $1.45 \times 10^{7} \mathrm{M}^{-1}$ at $37^{\circ} \mathrm{C}$ (Herbert et al., 1986). The binding constant of the interaction between $\lambda \mathrm{P}_{\mathrm{R}}$ promoter and holo RNAP is $2.7 \times 10^{7}$ $\mathrm{M}^{-1}$ at $28^{\circ} \mathrm{C}$ (Saecker et al., 2002). We obtained values of $K_{\text {app }}$ equal to $2.44 \times 10^{6} \mathrm{M}^{-1}$ and $4 \times 10^{7} \mathrm{M}^{-1}$ for lac166 and gal178, respectively (Tables 1 and 2), which are consistent with the results obtained by others, as discussed above.

The $K_{\text {app2 }}$ of the gal178-holo RNAP interaction is equal to $7.7 \times 10^{5} \mathrm{M}^{-1}$, and similar to the binding constant of core RNAP-DNA interactions. Earlier studies of nonspecific interactions of holo RNAP with DNA indicate the value $1 \times 10^{5} \mathrm{M}^{-1}$ (deHaseth et al., 1978). It confirms the hypothesis about a nonspecific interaction of a second enzyme molecule with gal178, and the higher value of $K_{\text {app }}$ is probably a result of a two-fold lower ionic strength in our experiment than in the earlier one.

The next step of the present studies was conducted in the presence of CRP. As an enhancer of transcription, it inhibits its start from the P1 sites of both promoters, lac and gal (Nisseley et al., 1971; Yu \& Reznikoff, 1985; Choy \& Adhya, 1993). The determination of the apparent binding constants allowed us to analyse quantitatively the obtained values at different CRP concentrations and to show an influence of CRP on the specific and nonspecific binding of RNAP to DNA.

The $K_{\text {app }}$ of the core RNAP-lac166 complex was two times higher in experiments with CRP than without it. In the case of the core RNAP-gal178 complex a new process appeared, i.e. the binding of a second enzyme molecule to the promoter sequence. $K_{\mathrm{app} 1}$ and $K_{\mathrm{app} 2}$ measured with CRP are 15 times higher and six times lower than without CRP, respectively. Because of the saturation of the specific sites and in the absence of nonspecific CRP-DNA interactions (which are reasonable, according to experiment conditions), this equilibrium shift should be explained by a specific CRP-DNA interaction.

There are two mechanisms of transcription activation by CRP: protein-induced DNA bending (angle of about $80^{\circ}$ ) and protein-protein interactions between CRP and RNAP determinants (Lawson et al., 2004). Both of them could also enhance the formation of the core RNAP-DNA-CRP complex. It explains also the two-molecule mechanism of the core RNAP-gal178 interaction in the presence of CRP. $\mathrm{CRP}$ can force asymmetrical binding of core RNAP to DNA. In effect, a long enough DNA fragment is exposed and the next core RNAP molecule is bound to the promoter. The difference of the measured $K_{\text {app }}$ for the two nonspecific core RNAP-DNA interactions can result from the different lengths of the promoters fragments. The shorter sequence in the case of the core RNAP-CRP-gal178 complex has a lower affinity than the whole fragment of DNA.

Similar results were obtained in the experiments with holo RNAP. The studies for lac166 were conducted with two forms of CRP: its wild type and the T158A variant mutated in AR1. According to the data obtained so far, T158 plays a key role 
in class I promoter activation. Its replacement by alanine decreased the transcription activation in vivo substantially (Gaal et al., 1996; Niu et al., 1996). Also, the RNAP-CRP interaction, in the absence of the promoter sequence was disturbed by this mutation (Heyduk et al., 1993). Surprisingly, we did not observe any significant differences between CRPwt and its mutant. There are many interactions during the transcription complex formation and the disturbance of only one of them could be too little to be visible. Furthermore, we observed only the formation of the closed complex, and the effect of the mutation could be stronger during the next steps of transcription, like open complex formation.

The $K_{\text {app }}$ of the complex formation was two times higher in the presence of CRPwt or its mutant than in their absence. In kinetic experiments conducted under similar conditions, $K_{\text {app }}$ increased 3.7and 1.8-fold in the case of promoters lac and $\mathrm{lacP}_{1-6}$ (an artificial, stronger promoter), respectively, when experiments without and with CRPwt were compared (Liu et al., 2003; 2004). The difference between the values obtained with the use of kinetic and fluorescence anisotropy methods can be explained by the use of a promoter which excluded polymerase binding to the P2 site in the kinetics studies, in contrast to our studies with an unmodified promoter. Holo RNAP binds preferentially to the lacP2 site in the absence of CRP in vitro, therefore the P1lac site is inaccessible (Peterson et al., 1985). On the other hand, promoter-bound CRP is a P2 site repressor (Yu \& Reznikoff, 1985). As a result of that, the measured $K_{\text {app }}$ in the presence of CRP is compared with two binding processes of RNAP to promoter sites in the absence of CRP. The stronger interaction of holo RNAP with lacP2 than with lacP1 explains the low amplitude of the observed change.

The holo RNAP-gal178-CRP complex was analysed on the basis of comparison of three CRP variants: CRPwt, CRPH19A and CRPH21A mutants. These amino-acid residues are part of AR2, which interacts with "165" determinant of $\alpha$ NTD. Their replacement with alanine induced a 5-fold decrease of in vitro transcription on $C C(-41,5)$ promoter (Niu et al., 1996).

The BB model was the best to describe the observed mechanism. In studies using mutants, the measured $K_{\text {app } 1}$ was, frequently higher than the one determined in the absence of CRP (Table 2). The best dispersion of the residuals was observed for the model in which $K_{\text {app1 }}$ was of the order of $10^{8}-10^{9}$ $\mathrm{M}^{-1}$ (Fig. 2). A limitation of the number of parameter by using a fixed value of $K_{\text {app } 1}$ (see Table 2) was necessary to obtain correct parameter values as in the case of the systems with CRPwt. That solution did really improve the fit quality. The necessity of using different ways of analysis points to the diversity in the behaviour of different CRP forms. The lower $K_{\text {app1 }}$ values obtained in the presence of the CRP mutants indicate a defect in the ability of CRP to induce an equilibrium shift to the specific complex. Unfortunately, the correlation between the measured $K_{\text {app } 1}$ and the CRP concentration was poor; therefore we could not calculate the quantitative effect of the CRP presence more precisely. We determined that the presence of CRP induced a 3to 25-fold increase of the $K_{\text {app }}$ of complex formation. This effect was comparable to the one derived from kinetic experiments, where a 4- to 10-fold increase was observed (Herbert et al., 1986; Goodrich \& McClure, 1992; Roy et al., 2004). This result is a positive verification of the applied analysis.

According to earlier assumptions, the lower binding constant, $K_{\mathrm{app} 2}$ describes nonspecific holo RNAP-DNA interaction. Indeed, its values were insensitive to CRP types and their concentration and they are equal to $10^{6} \mathrm{M}^{-1}$.

Our studies confirm the structural role of CRP in the transcription activation mechanism of lacP1 and galP1 promoters. Its presence enhances the affinity of both RNAP forms: core and holo to the promoter sequence by inducing additional interactions. The protein-protein interactions and/or DNA bending induced by CRP change the core RNAP-DNA interaction from nonspecific to specific.

\section{Acknowledgements}

This study was partly supported by grant No. 3P04A00624 from the Ministry of Science and Higher Education.

\section{REFERENCES}

Aiba H, Fujimoto S, Ozaki N (1982) Molecular cloning and nucleotide sequencing of the gene for $E$. coli cAMP receptor protein. Nucleic Acids Res 10: 1345-1361.

Bell A, Gaston K, Williams R, Chapman K, Kolb A, Buc H, Minchin S, Williams J, Benoff B, Yang H, Lawson CL, Parkinson G, Liu J, Blatter E, Ebright YW, Berman HM, Ebright RH (2002) Structural basis of transcription activation: the CAP-alpha CTD-DNA complex. Science 297: 1562-1566.

Busby S (1990) Mutations that alter the ability of the Escherichia coli cyclic AMP receptor protein to activate transcription. Nucleic Acids Res 18: 7243-7250.

Busby S, Ebright RH (1999) Transcription activation by catabolite activator protein (CAP). J Mol Biol 293: 199-213.

Busby S, Kotlarz D, Buc H (1983) Deletion mutagenesis of the Escherichia coli galactose operon promoter region. $J$ Mol Biol 154: 211-227.

Choy HE, Adhya S (1992) Control of gal transcription through DNA looping: inhibition of the initial transcribing complex. Proc Natl Acad Sci USA 89: 1126411268.

Choy HE, Adhya S (1993) RNA polymerase idling and clearance in gal promoters: use of supercoiled minicir- 
cle DNA template made in vivo. Proc Natl Acad Sci USA 90: 472-476.

Craig ML, Tsodikov OV, McQuade KL, Schlax PE Jr, Capp MW, Saecker RM, Record MT Jr (1998) DNA footprints of the two kinetically significant intermediates in formation of an RNA polymerase-promoter open complex: evidence that interactions with start site and downstream DNA induce sequential conformational changes in polymerase and DNA. J Mol Biol 283: 741-756.

deHaseth PL, Lohman TM, Burgess RR, Record MT Jr (1978) Nonspecific interactions of Escherichia coli RNA polymerase with native and denatured DNA: differences in the binding behavior of core and holoenzyme. Biochemistry 17: 1612-1622.

deHaseth PL, Zupancic ML, Record MT Jr (1998) RNA polymerase-promoter interactions: the comings and goings of RNA polymerase. J Bacteriol 180: 30193025.

Ebright RH (1993) Transcription activation at Class I CAPdependent promoters. Mol Microbiol 8: 797-802.

Ebright RH, Ebright YW, Gunasekera A (1989) Consensus DNA site for the Escherichia coli catabolite gene activator protein (CAP): CAP exhibits a 450-fold higher affinity for the consensus DNA site than for the $E$ coli lac DNA site. Nucleic Acids Res 17: 10295-10305.

Gaal T, Ross W, Blatter EE, Tang H, Jia X, Krishnan VV, Assa-Munt N, Ebright RH, Gourse RL (1996) DNAbinding determinants of the alpha subunit of RNA polymerase: novel DNA-binding domain architecture. Genes Dev 10: 16-26.

Giraud-Panis MJ, Toulme F, Blazy B, Maurizot JC, Culard F (1994) Fluorescence study on the non-specific binding of cyclic-AMP receptor protein to DNA: effect of $\mathrm{pH}$. Biochimie 76: 133-139.

Goodrich JA, McClure WR (1992) Regulation of open complex formation at the Escherichia coli galactose operon promoters. Simultaneous interaction of RNA polymerase, gal repressor and CAP/CAMP. J Mol Biol 224: 1529.

Herbert M, Kolb A, Buc H (1986) Overlapping promoters and their control in Escherichia coli: the gal case. Proc Natl Acad Sci USA 83: 2807-2811.

Hernandez VJ, Hsu LM, Cashel M (1996) Conserved region 3 of Escherichia coli final sigma70 is implicated in the process of abortive transcription. J Biol Chem 271: 18775-18779.

Heyduk T, Lee JC (1990) Application of fluorescence energy transfer and polarization to monitor Escherichia coli cAMP receptor protein and lac promoter interaction. Proc Natl Acad Sci USA 87: 1744-1748.

Heyduk T, Lee JC, Ebright YW, Blatter EE, Zhou Y, Ebright RH (1993) CAP interacts with RNA polymerase in solution in the absence of promoter DNA. Nature 364: 548-549.

Kabata H, Kurosawa O, Arai I, Washizu M, Margarson SA, Glass RE, Shimamoto N (1993) Visualization of single molecules of RNA polymerase sliding along DNA. Science 262: 1561-1563.

Kolb A, Busby S, Buc H, Garges S, Adhya S (1993) Transcriptional regulation by cAMP and its receptor protein. Annu Rev Biochem 62: 749-795.

Kuzmic P (1996) Program DYNAFIT for the analysis of enzyme kinetic data: application to HIV proteinase. Anal Biochem 237: 260-273.

Lawson CL, Swigon D, Murakami KS, Darst SA, Berman HM, Ebright RH (2004) Catabolite activator protein: DNA binding and transcription activation. Curr Opin Struct Biol 14: 10-20.
Leu SF, Baker CH, Lee EJ, Harman JG (1999) Position 127 amino acid substitutions affect the formation of CRP:cAMP:lacP complexes but not CRP:cAMP: RNA polymerase complexes at lacP. Biochemistry 38 : 6222-6230.

Liu M, Gupte G, Roy S, Bandwar RP, Patel SS, Garges S (2003) Kinetics of transcription initiation at lacP1. Multiple roles of cyclic AMP receptor protein. J Biol Chem 278: 39755-39761.

Liu M, Tolstorukov M, Zhurkin V, Garges S, Adhya S (2004) A mutant spacer sequence between -35 and -10 elements makes the Plac promoter hyperactive and cAMP receptor protein-independent. Proc Natl Acad Sci USA 101: 6911-6916.

Malan TP, Kolb A, Buc H, McClure WR (1984) Mechanism of CRP-cAMP activation of lac operon transcription initiation activation of the P1 promoter. J Mol Biol 180: 881-909.

Malecki J, Polit A, Wasylewski Z (2000) Kinetic studies of cAMP-induced allosteric changes in cyclic AMP receptor protein from Escherichia coli. J Biol Chem 275: 8480-8486.

McKay DB, Steitz TA (1981) Structure of catabolite gene activator protein at 2.9 A resolution suggests binding to left-handed B-DNA. Nature 290: 744-749.

Murakami K, Fujita N, Ishihama A (1996) Transcription factor recognition surface on the RNA polymerase alpha subunit is involved in contact with the DNA enhancer element. EMBO J 15: 4358-4367.

Naryshkin N, Revyakin A, Kim Y, Mekler V, Ebright RH (2000) Structural organization of the RNA polymerasepromoter open complex. Cell 101: 601-611.

Nisseley SP, Anderson WB, Gottesman ME, Perlman RL, Pastan I (1971) In vitro transcription of the gal operon requires cyclic adenosine monophosphate and cyclic adenosine monophosphate receptor protein. J Biol Chem 246: 4671-4678.

Niu W, Zhou Y, Dong Q, Ebright YW, Ebright RH (1994) Characterization of the activating region of Escherichia coli catabolite gene activator protein (CAP). I Saturation and alanine-scanning mutagenesis. J Mol Biol 243: 595-602.

Niu W, Kim Y, Tau G, Heyduk T, Ebright RH (1996) Transcription activation at class II CAP-dependent promoters: two interactions between CAP and RNA polymerase. Cell 87: 1123-1134.

Ozoline ON, Tsyganov MA (1995) Structure of open promoter complexes with Escherichia coli RNA polymerase as revealed by the DNase I footprinting technique: compilation analysis. Nucleic Acids Res 23: 4533-4541.

Passner JM, Schultz SC, Steitz TA (2000) Modeling the cAMP-induced allosteric transition using the crystal structure of CAP-cAMP at $2.1 \AA$ resolution. J Mol Biol 304: 847-859.

Peterson ML, Reznikoff WS (1985) Properties of lac P2 in vivo and in vitro. An overlapping RNA polymerase binding site within the lactose promoter. J Mol Biol 185: 535-543.

Pyles EA, Lee JC (1998) Escherichia coli cAMP receptor protein-DNA complexes. 2. Structural asymmetry of DNA bending. Biochemistry 37: 5201-5210.

Ren YL, Garges S, Adhya S, Krakow JS (1988) Cooperative DNA binding of heterologous proteins: evidence for contact between the cyclic AMP receptor protein and RNA polymerase. Proc Natl Acad Sci USA 85: 41384142.

Rhodius VA, Busby SJ (2000) Interactions between activating region 3 of the Escherichia coli cyclic AMP receptor protein and region 4 of the RNA polymerase sigma(70) 
subunit: application of suppression genetics. I Mol Biol 299: 311-324.

Rhodius VA, Busby SJ (2000) Transcription activation by the Escherichia coli cyclic AMP receptor protein: determinants within activating region 3. J Mol Biol 299: 295-310.

Ross W, Gourse RL (2005) Sequence-independent upstream DNA-alphaCTD interactions strongly stimulate Escherichia coli RNA polymerase-lacUV5 promoter association. Proc Natl Acad Sci USA 102: 291-296.

Roy S, Semsey S, Liu M, Gussin GN, Adhya S (2004) GalR represses galP1 by inhibiting the rate-determining open complex formation through RNA polymerase contact: a GalR negative control mutant. J Mol Biol 344: 609618.

Saecker RM, Tsodikov OV, McQuade KL, Schlax PE Jr, Capp MW, Record MT Jr (2002) Kinetic studies and structural models of the association of $E$. coli sigma(70) RNA polymerase with the lambdaP(R) promoter: large scale conformational changes in forming the kinetically significant intermediates. J Mol Biol 319: 649-671.

Sakata-Sogawa K, Shimamoto N (2004) RNA polymerase can track a DNA groove during promoter search. Proc Natl Acad Sci USA 101: 14731-14735.

Savery NJ, Lloyd GS, Kainz M, Gaal T, Ross W, Ebright RH, Gourse RL, Busby SJ (1998) Transcription activation at Class II CRP-dependent promoters: identification of determinants in the C-terminal domain of the RNA polymerase alpha subunit. EMBO J 17 : 3439-3447.

Severinov K, Soushko M, Goldfarb A, Nikiforov V (1993) Rifampicin region revisited. New rifampicin-resistant and streptolydigin-resistant mutants in the beta subunit of Escherichia coli RNA polymerase. J Biol Chem 268: 14820-14825.

Straney DC, Straney SB, Crothers DM (1989) Synergy between Escherichia coli CAP protein and RNA polymerase in the lac promoter open complex. J Mol Biol 206: 41-57.

Takahashi M, Blazy B, Baudras A, Hillen W (1989) Ligand-modulated binding of a gene regulatory protein to DNA. Quantitative analysis of cyclic-AMP induced binding of CRP from Escherichia coli to non-specific and specific DNA targets. J Mol Biol 207: 783-796.

Tang H, Severinov K, Goldfarb A, Ebright RH (1995) Rapid RNA polymerase genetics: one-day, no-column preparation of reconstituted recombinant Escherichia coli RNA polymerase. Proc Natl Acad Sci USA 92: 49024906.

Tang H, Kim Y, Severinov K, Goldfarb A, Ebright RH (1996) Escherichia coli RNA polymerase holoenzyme: rapid reconstitution from recombinant alpha, beta, beta', and sigma subunits. Methods Enzymol 273: 130134.

Taniguchi T, de Crombrugghe B (1983) Interactions of RNA polymerase and the cyclic AMP receptor protein on DNA of the E. coli galactose operon. Nucleic Acids Res 11: 5165-5180.

Taniguchi T, O'Neill M, de Crombrugghe B (1979) Interaction site of Escherichia coli cyclic AMP receptor protein on DNA of galactose operon promoters. Proc Natl Acad Sci USA 76: 5090-5094.

Tsujikawa L, Tsodikov OV, deHaseth PL (2002) Interaction of RNA polymerase with forked DNA: evidence for two kinetically significant intermediates on the pathway to the final complex. Proc Natl Acad Sci USA 99: 3493-3498.

Ushida C, Aiba H (1990) Helical phase dependent action of CRP: effect of the distance between the CRP site and the -35 region on promoter activity. Nucleic Acids Res 18: $6325-6330$.

Vogel SK, Schulz A, Rippe K (2002) Binding affinity of Escherichia coli RNA polymerase*sigma54 holoenzyme for the glnAp2, nifH and nifL promoters. Nucleic Acids Res 30: 4094-4101.

Weber IT, Steitz TA (1987) Structure of a complex of catabolite gene activator protein and cyclic AMP refined at $2.5 \AA$ A resolution. J Mol Biol 198: 311-326.

Williams R, Bell A, Sims G, Busby S (1991) The role of two surface exposed loops in transcription activation by the Escherichia coli CRP and FNR proteins. Nucleic Acids Res 19: 6705-6712.

Yu XM, Reznikoff WS (1985) Deletion analysis of the Escherichia coli lactose promoter P2. Nucleic Acids Res 13: 2457-2468.

Zalenskaya K, Lee J, Gujuluva CN, Shin YK, Slutsky M, Goldfarb A (1990) Recombinant RNA polymerase: inducible overexpression, purification and assembly of Escherichia coli rpo gene products. Gene 89: 7-12.

Zhou Y, Merkel TJ, Ebright RH (1994) Characterization of the activating region of Escherichia coli catabolite gene activator protein (CAP). II. Role at Class I and class II CAP-dependent promoters. J Mol Biol 243: 603-610. 